operational expenses incurred by the office. Expenses should be split into direct new business, direct renewal, selling and overheads. An expense analysis ought to be carried out to measure these and subsequently actual expenses must be monitored against forecast.

There are four principal sales outlets: direct sales, broker, professional intermediary and mass marketing. With direct salesmen the overall acquisition cost is generally higher and one has the problem of selection and training. However, within reason the office has control over their activities. The broker acquisition costs are generally lower but the office has no control over them and often the contract needs to be quite competitive. Mass marketing is still in its infancy in this country.

\title{
COMPUTER TECHNIQUES FOR DEVELOPING PREMIUM RATES
}

\author{
by \\ N. STEPHENS \\ (Synopsis of a paper presented to the Society on 17 February 1981)
}

The paper shows the basic methods used to produce premium rates on a computer. It is aimed primarily at students but would also be of interest to those in the actuarial profession who have previously used only commutation functions to evaluate premium rates.

The paper is in two parts - the first showing how, by returning to first principles and summing all values, commutation functions are no longer required. The second part gives the basic steps required to produce a cash flow program which may be used to check premium rates, profitability and bonus levels of new or existing policies. Whilst commutation functions may still have a place in actuarial calculations it is not possible to employ them where, for instance, interest rates are assumed to vary with elapsed term or where withdrawal rates also are included as a decrement. The paper shows how these sorts of assumptions can be simply included in a computer model, although it is pointed out that the results obtained should be carefully compared with rates produced assuming level interest rates and no withdrawals.

Numerous simple flow diagrams are used to demonstrate the 
methods used to calculate, store and print premium rates. At the end of the section it is shown how annuity rates may also be computerized, in particular a flow diagram for calculating capital-protected escalating annuities is included.

The second part of the paper, dealing with cash flow programs, gives some examples to show how the premium rates calculated in the first part may be checked. (The projected fund per life at the end of the term of an endowment assurance being equal to the estimated maturity value of each policy.)

Using the same program for a group of policies which have already been in force a number of years it is thus possible to ascertain whether there will be sufficient moneys available on differing future assumptions to meet the maturity liabilities as they emerge.

\title{
THE FINANCING OF PRIVATE OCCUPATIONAL PENSION SCHEMES
}

by

\author{
R. B. ABRAMSON AND S. A. CARNE
}

(Synopsis of a paper presented to the Society on 20 January 1981)

IN the U.K. and the U.S.A. most occupational pension schemes are funded in advance; in France such schemes are run on a pay-asyou-go basis; in West Germany, book (or internal) reserves are the predominant method. There is a tendency for each nation to regard its own method as the most suitable. In this paper the authors have set out to examine the principles of these various systems of pension financing, not in order to advocate any particular system but rather to promote a better understanding.

Companies in the private sector must be profitable if they are to survive. The authors devote a substantial part of the paper to analysing the effects of each financing method on the profits of the supporting employer. The popular view is that funding is cheaper if the assets earn a real return (and more expensive otherwise); this is shown to be a myth. Arguments are put which show that where a whole industry opts for pay-as-you-go the level of profits will be much the same as if the pensions had been funded in advance--it is the price of the industry's products that will differ. 